http://jmscr.igmpublication.org/home/ ISSN (e)-2347-176x ISSN (p) 2455-0450

crossref DOI: https://dx.doi.org/10.18535/jmscr/v8i9.02

\title{
Knowledge and Attitude to Information Gathering Practices Related to Covid-19: A Cross Sectional Study of Health Care Workers in Kerala
}

\author{
Author
}

\section{Dr Farha Ahmed Payyanil Karlath}

Junior Resident, Department of Internal Medicine, Government Medical College, Kannur, Kerala, India

\begin{abstract}
SARS-CoV 2 is the most recently discovered coronavirus that causes Coronavirus Disease 2019 (COVID19). The World Health Organization declared COVID19 as a pandemic on $11^{\text {th }}$ March 2020.The number of cases and mortality associated with it is increasing day by day. Various measures have been deployed by the competent authorities in order to optimally educate healthcare workers.

Along with assessment of the prevailing knowledge among healthcare workers to identify critical gaps that need to be addressed, my study also aimed to gather insight into the resources used and efforts made by healthcare workers to keep up with the latest developments taking place related to the pandemic.
\end{abstract}

\section{Materials and Methods}

\section{Design}

A web based cross sectional study was conducted in June 2020 using a self designed survey after reviewing guidelines issued by the Indian Council of Medical Research (ICMR) and MoHFW of India.

\section{Tool}

The self administered questionnaire consisted of 38 questions of which 24 were used to assess knowledge about COVID-19, namely, the epidemiology, its diagnosis and clinical features, prevention and personal protection equipments (PPE) and treatment and complications. The remaining 14 questions were directed at evaluating the attitude for information gathering practices, the resources used by healthcare workers and to assess the satisfaction of healthcare workers with the available sources.

\section{Sample}

Healthcare workers (physicians, interns, medical students, dentists and nurses) were approached using online communication platforms. Convenience sampling was used. Informed consent was obtained from all the participants and their responses were kept confidential.

\section{Analysis}

Data was analysed using SPSS version 24."t-test" was performed to compare independent variables (such as gender, age, designation) against dependent variables (such as \% correct scores). The differences was considered statistically significant if $\mathrm{p}$ value was $<0.05$. 


\begin{tabular}{|l|l|l|l|}
\hline \multicolumn{4}{|c|}{ Table 1 : Demographic Characteristics of the HCWs } \\
\hline Characteristics & Subgroups & $\begin{array}{l}\text { Number } \\
(\mathbf{N})\end{array}$ & $\begin{array}{l}\text { Percentage } \\
(\%)\end{array}$ \\
\hline \multirow{3}{*}{ Gender } & Male & 159 & 57.8 \\
& Female & 116 & 42.2 \\
\hline Age & Less than 20 yrs & 27 & 9.8 \\
& $21-25$ & 158 & 57.5 \\
& $26-30$ & 51 & 18.5 \\
& $31-35$ & 11 & 4.0 \\
& $36-40$ & 7 & 2.5 \\
& $40-45$ & 6 & 2.2 \\
& More than 45 & 14 & 5.1 \\
\hline
\end{tabular}

\begin{tabular}{|c|c|c|}
\hline Characteristic & $\begin{array}{l}\text { Knowledge (mean \% } \\
\text { correct responses) }\end{array}$ & P -value \\
\hline \multicolumn{3}{|l|}{ Actively involved in Patient care } \\
\hline Yes & $54.96+/-10.77$ & \multirow[t]{2}{*}{0.001} \\
\hline No & $50.78+/-8.82$ & \\
\hline \multicolumn{3}{|l|}{ Designation } \\
\hline Medical Students & $50.33+/-8.54$ & \multirow[t]{2}{*}{0.001} \\
\hline Interns & $58.15+/-8.71$ & \\
\hline Medical Students & $50.33+/-8.54$ & \multirow[t]{2}{*}{0.001} \\
\hline PG Residents & $56.13+/-9.35$ & \\
\hline Medical Students & $50.33+/-8.54$ & \multirow[t]{2}{*}{0.048} \\
\hline SRs & $55.65+/-12.06$ & \\
\hline Medical Students & $50.33+/-8.54$ & \multirow[t]{2}{*}{0.009} \\
\hline Consultants & $56.57+/-12.01$ & \\
\hline \multicolumn{3}{|l|}{ Data Gathering Practices } \\
\hline Govt Websites & $53.81+/-8.76$ & \multirow[t]{2}{*}{0.006} \\
\hline Social Media & $47.08+/-9.57$ & \\
\hline Online Courses & $56.21+/-7.75$ & \multirow[t]{2}{*}{0.015} \\
\hline Social Media & $47.08+/-9.57$ & \\
\hline \multicolumn{3}{|l|}{ Covid 19 Training in Institution } \\
\hline Yes & $54.80+/-9.82$ & \multirow[t]{2}{*}{0.003} \\
\hline No & $50.81+/-10.26$ & \\
\hline
\end{tabular}

\section{Results}

\section{Demographics}

Response rate was $40.1 \%$ and completion rate was 97.8\%.Table 1 show, $57.5 \%$ of the responders were 21-25 years old $(\mathrm{n}=158)$. Males included $57.8 \%(\mathrm{n}=159)$.

\section{Knowledge about COVID 19}

Respondents showed suboptimal knowledge. Noteworthy findings were-

- Only $53.1 \%$ knew which patients were eligible for COVID 19 testing as per ICMR guidelines.

- Mere $48 \%$ were aware of the correct order of donning PPE.
- Participants also had insufficient knowledge about the pertinent common lab investigation findings for COVID 19.

- While 92.7\% knew ARDS to be a potential complication of COVID 19, poor knowledge was observed regarding other complications.

As shown in table 2, knowledge was assessed based on \% correct responses. Mean of \% correct responses in the study sample was found to be $52.89 \%$ (SD +/- 9.83\%). Healthcare workers currently involved in providing patient care had significantly higher mean $\%$ compared to those who weren't $(\mathrm{p}=0.001)$. Healthcare workers who had received formal training or guidelines from their institution reported significantly higher knowledge $(\mathrm{p}=0.003)$. 


\section{Attitude}

The amount of effort put by respondents to gather knowledge significantly co-related with \% correct responses $(\mathrm{p}=0.043)$.

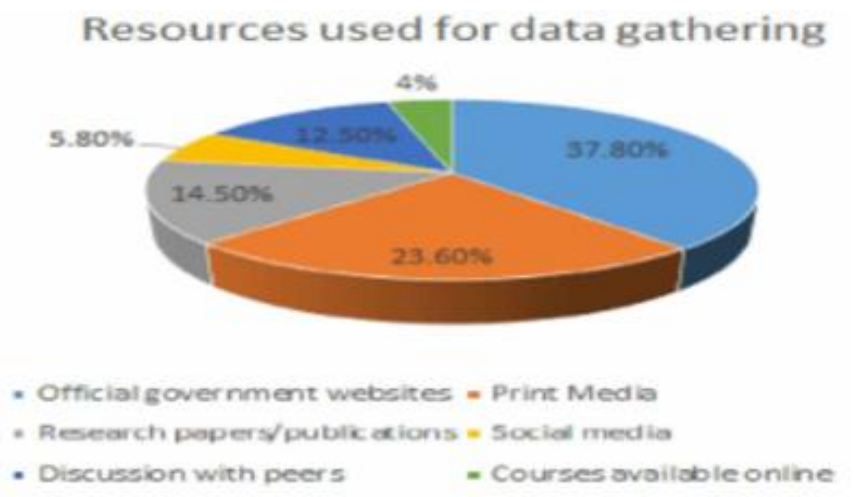

\section{Resources}

Individuals using social media reported significantly lower \% correct responses as compared to official government websites $(\mathrm{p}=0.006)$, research papers (0.019) and online courses $(p=0.015) .91 .5 \%$ felt the need for responsible authorities to provide a more uniform, readily available sources of information.

\section{Discussion}

- My findings suggest that standardised education interventions by institutions can have a remarkable impact on the awareness of healthcare workers.

- My results offer compelling evidence for further evaluation of knowledge amongst healthcare workers at a larger scale.

- Greater motivation is needed for healthcare workers to access official sources of information instead of social media platforms as they may not be reliable. This was also observed by Bhagavathula et al in their study done in UAE.

\section{Conclusion}

As COVID 19 pandemic unfolds, healthcare workers play a pivotal role in promptly diagnosing and treating cases. The world has been hard hit and it is the need of the hour to identify and bridge critical knowledge gaps in healthcare workers in providing proper training and authentic sources of information to improve the understanding of this novel disease.

\section{References}

1. Ministry of Health \& Family Welfare, Government of India. Resource material for Capacity Building of Healthcare Professionals for COVID-19 Containment.

2. Bhagavathula AS, Aldhaleei WA Rahmani J, Mahabadi MA, Bandari DK. Novel coronavirus (COVID-19) knowledge and perceptions: a survey of healthcare workers. MedRxiv. 2020. 